\title{
Programming of body composition by early growth and nutrition
}

\author{
Jonathan C. K. Wells*, Sirinuch Chomtho and Mary S. Fewtrell \\ Childhood Nutrition Research Centre, Institute of Child Health, 30 Guilford Street, London WC1N 1EH, UK
}

\begin{abstract}
There is now compelling evidence that growth patterns in early life are associated with risk of the metabolic syndrome in adulthood, although the relative importance of prenatal $v$. postnatal growth for such associations remains controversial. Body composition may play a key role in the 'programming' of such diseases, through itself being programmed by early growth, and perhaps also by being a mediator of the programming process. Early studies reporting positive associations between birth weight and adult BMI suggested a tendency for large babies to become obese adults. Such findings appeared contradictory to the many studies linking low birth weight with increased risk of the metabolic syndrome. Recent studies now indicate that birth weight is strongly predictive of later lean mass, and has a much weaker association with later fatness. Studies that link low birth weight with a more central adipose distribution in later life remain controversial, and require confirmation using more sophisticated methodologies. Findings for infant growth rate appear population-specific, with infant weight gain predicting subsequent lean mass in developing countries, but predicting subsequent fat mass and obesity in industrialised populations. Further studies are required on this issue, to ensure that appropriate public health policies are recommended for countries across the range of economic development. Although the links between early growth and later disease risk implicate early-life nutrition, either in utero or during infancy, few prospective studies have explored the influence of early diet on later body composition. Many studies have associated breast-feeding with a reduced prevalence of obesity categorised by BMI; however, the few studies directly evaluating childhood fatness provide little support for this hypothesis. Recent advances in the ability to measure body composition during the infant period offer a major opportunity to improve the understanding of the nutritional programming of body composition and its contribution, or lack thereof, to subsequent disease risk.
\end{abstract}

Body composition: Nutritional programming: Birth weight: Infant growth rate

In the last two decades a large volume of evidence has emerged associating growth patterns during early life with subsequent risk of the metabolic syndrome, implicating early-life nutrition as the underlying mechanism (Barker et al. 2002; Wells, 2007). The importance of early development for later health outcomes is reflected in the concept of programming, i.e. the notion that during early ontogeny the developing organism passes through 'critical windows' of sensitivity or plasticity, during which environmental factors generate long-lasting variability in phenotype (Lucas, 1991).

Whilst the relative importance of fetal $v$. postnatal growth for later disease risk remains controversial, it is no longer doubted that experience during early life is predictive of a variety of health outcomes, including body size, body composition and the risk of diseases such as hypertension, stroke, type 2 diabetes, obesity and CVD (Barker et al. 2002). Such work is supported by complementary research, much of it involving experimental interventions, in a variety of animal species (McMillen \& Robinson, 2005).

The majority of studies associating early development with later disease have used birth weight as an index of fetal growth, with low birth weight being shown to be predictive of increased subsequent disease risk. In many cases the strongest association between birth weight and later outcome is found when a statistical adjustment for adult size is incorporated (Barker et al. 2002). This issue has more than one implication. First, it has been argued (Lucas et al. 1999) that such statistical models do not demonstrate that low birth weight is the key risk factor, rather that change in size between birth and adulthood is 
most important. Thus, postnatal growth rate as well as fetal growth rate appears to be implicated in the disease process. Such a perspective does not discount the importance of fetal growth, since the worst outcome is often found in those babies born small who subsequently become large (Adair \& Cole, 2002; Barker et al. 2002). However, lowbirth-weight babies usually display the fastest rate of infant growth, while a faster trajectory of childhood growth has also been linked with increased disease risk (Barker et al. 2005).

The second issue raised by the statistical analyses is that adult BMI often makes an important contribution to the interaction between early growth patterns and subsequent disease risk. Adult obesity is now well established as a risk factor for the metabolic syndrome, and BMI is widely used as an index of obesity; however, across the entire range of body weight there is a correlation between BMI and lean mass as well as fatness. Furthermore, BMI is not very strongly correlated with the central abdominal fat now considered most harmful to health (Wells et al. 2007). The strong statistical contribution of BMI to analyses associating early growth with later outcome does not, therefore, reveal which component, or components, of body composition are most important. Since epidemiological studies have typically used diseases as their primary outcome, there is a need to improve the understanding of how tissues and organs themselves are programmed. Early growth patterns might induce long-term effects on body composition, e.g. by impacting on hormonal axes that in turn regulate childhood growth. Alternatively, body composition variability might be a central component of early growth variability, and track from fetal life or infancy onwards.

Over the last decade an increasing number of studies have explored the programming of body composition in more detail. The primary aim here is to review such research, considering different periods of growth and their impact on total tissue masses and their regional distribution. A secondary aim is to consider the potential role of early-life nutrition in accounting for such associations. However, before reviewing this literature it is important to consider the difficulty of evaluating body composition in the epidemiological studies that are required to investigate such associations.

\section{Indices of body composition in epidemiological research}

The large sample sizes that are characteristic of epidemiological research generally preclude access to the most sophisticated body-composition techniques. Studies are therefore obliged to rely on simple techniques, which often only assess the outcome indirectly. Body composition comprises not only tissue masses but also aspects of size and shape. However, the ability to differentiate these variables becomes more difficult when indices of size and shape are themselves used to predict tissue masses.

The limitations of BMI as an index of adiposity are becoming increasingly appreciated. In children, for example, individuals of the same age and gender have a twofold range of body fat mass for a given BMI value (Wells 2000), as shown in Fig. 1(a), a scenario also present in those who are obese (Wells et al. 2006). Some children with high BMI are 'stocky' (high muscle mass) rather than fat, while other children within the normal BMI range nevertheless have high fat mass and relatively low muscle mass. BMI is therefore a poor outcome in epidemiological research investigating the possible programming of body composition and obesity. BMI also fails to reflect body shape and hence fat distribution, as shown in Fig. 1(b). Here, unpublished data for women from the UK National Sizing Survey (JCK Wells, P Treleaven and TJ Cole, unpublished results) illustrate how, after adjusting for hip girth, waist girth increases substantially with age within any given level of BMI.

Central adiposity has often been evaluated using the waist:hip ratio, or the triceps:subscapular skinfold thickness. These outcomes are likewise problematic in epidemiological analyses focusing on early growth. Differences between individuals in the waist:hip ratio may reflect physique (hip girth) as much as abdominal adiposity (waist girth). Fig. 1(c) plots waist circumference z-score $v$. hip circumference $\mathrm{z}$-score in approximately 2000 young adult women from the UK National Sizing Survey (JCK Wells, $\mathrm{P}$ Treleaven and TJ Cole, unpublished results). A high waist:hip ratio is present in all those individuals with values lying above the regression line; however, many of those with such a high waist:hip ratio nevertheless have a low waist girth. Skinfold thickness ratios have likewise been shown to have poor statistical validity. The relationship between limb and torso skinfolds is not linear, and dividing one skinfold by another is a problematic way of assessing relative fat distribution (Wells \& Victora, 2005). Similarly, percentage fat is a problematic way to express data for whole-body composition, since it reflects lean mass as well as fat and conceals absolute adiposity (Wells \& Victora, 2005).

These findings emphasise the importance when investigating the early-life programming of body composition of using both improved methodologies for measuring body composition and more-appropriate statistical analyses.

\section{Fetal growth and later body composition}

Interest in the relationship between size at birth and later body composition is not derived only from the proposed importance of low birth weight in the programming process. For obvious practical reasons size at birth offers the earliest opportunity to assess growth rate and body composition in detail. Paradoxically, however, remarkably few studies have obtained data more sophisticated than weight and length at birth, while it is also now appreciated that birth weight may not play a causal role in associations between early experience and later outcome. Birth weight is best regarded as an outcome of convenience (Wilcox, 2001), and its value in indexing fetal growth is confounded by a lack of knowledge about genetic potential. As discussed later (see p. 426), researchers have adopted different approaches to address these problems, but birth weight remains an imperfect index of fetal growth.

A much-cited source of evidence concerning the programming of body composition during fetal life comprises 
(a)

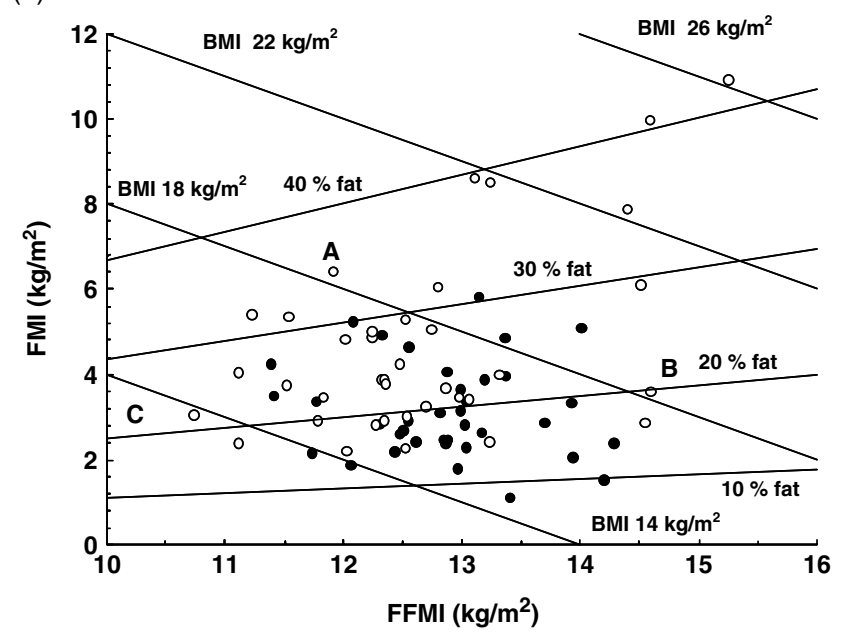

(b)

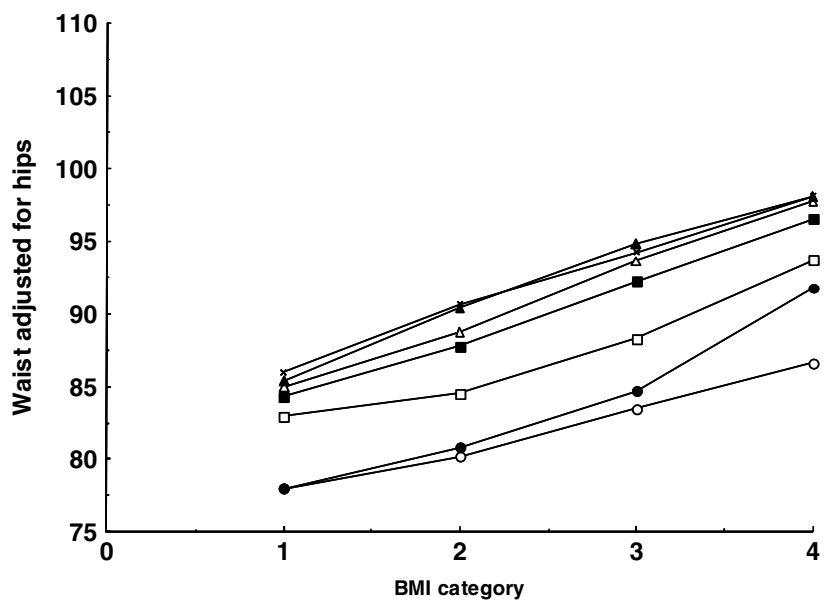

(c)

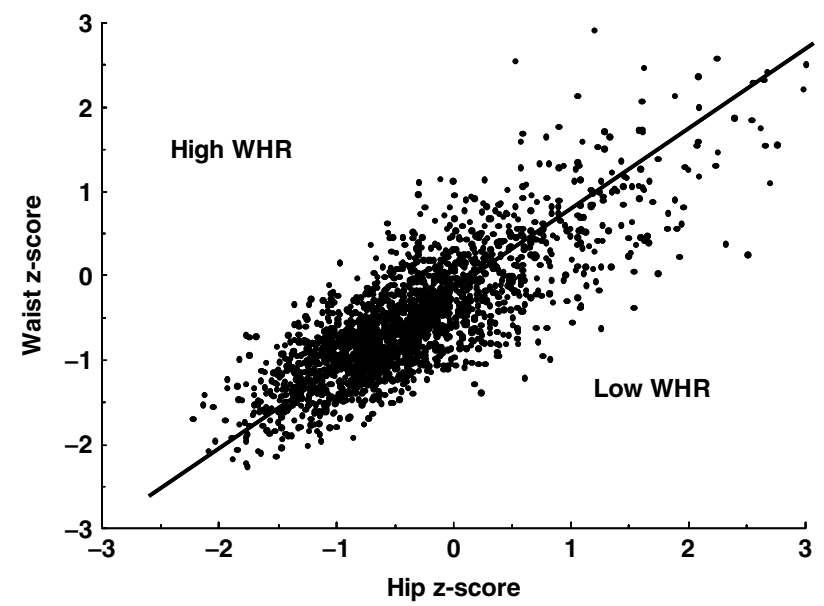

Fig. 1. Limitations of anthropometric indices for assessing body composition in epidemiological studies. (a) Hattori graph for children aged 8 years $(\bigcirc$, girls; $\boldsymbol{O}$, boys) showing fat mass adjusted for height (fat mass index; FMI) $v$. lean mass adjusted for height (fatfree mass index, FFMI). The individuals $A$ and $B$ represent two girls with similar BMI (approx $18 \mathrm{~kg} / \mathrm{m}^{2}$ ), but with A having twice the FMI of $B$. The individuals $B$ and $C$ have similar percentage fat, but very different BMI and FFMI. (b) The effect of age (years: $\bigcirc, 17-20$; the follow-up of individuals exposed to malnutrition in utero. During the Second World War several populations were exposed to substantially-reduced energy intakes for specific time periods. Studies of the Dutch 'hunger winter' (Stein et al. 2004) and the siege of Leningrad (Stanner \& Yudkin, 2001) have shown that maternal undernutrition during pregnancy is associated with drastic reductions in the rate of conception, and with deficits in mean birth weight of approximately 300-500 g. Analysing the Dutch data according to the trimester of undernutrition suggests that the majority of this weight deficit can be attributed to famine exposure during the third trimester (Stein et al. 2004). Subsequent follow-up of the Dutch population that focused on adult males at the age of military conscription (Ravelli et al. 1976) has found betweengroup differences in the prevalence of obesity categorised according to BMI. Those individuals exposed in early pregnancy (first and second trimesters) were found to have an increased prevalence of adult obesity relative to nonexposed subjects, whereas those exposed in late pregnancy or early infancy have a reduced obesity prevalence. Morerecent follow-ups (Ravelli et al. 1999) have found similar results for waist circumference in women but not men. However, these data are difficult to interpret. First, the findings were not replicated in survivors of the Leningrad siege, who were found to show no association between prenatal exposure to famine and subsequent obesity risk (Stanner \& Yudkin, 2001). Such negative findings have been attributed to the lack of catch-up growth in the Leningrad cohort, in contrast to the Dutch cohort (Stanner \& Yudkin, 2001). Second, there is no need to invoke the concept of fetal programming of obesity to explain these results. An alternative interpretation posits selective conception according to maternal genotype or phenotype (maternal fatness), or selective survival according to fetal genotype or phenotype (offspring thriftiness). Thus, associations between maternal malnutrition, birth weight and later obesity do not necessarily implicate fetal growth patterns as the underlying mechanism, and may simply represent the greater capacity of initially-fatter women to conceive during harsh conditions.

A second and stronger source of evidence for the fetal programming of body composition derives from investigation of the effect of gestational age at birth. It is well established that preterm infants have low levels of body fat at birth (Rigo et al. 1998), a condition that can be attributed to the fact that fat deposition occurs largely during the

, 21-30; $\square, 31-40 ; \mathbf{\square}, 41-50 ; \triangle, 51-60 ; \mathbf{\Lambda}, 61-70 ; \mathrm{x}, \geq 70)$ on the relationship between BMI (categories $1-4 ; \mathrm{kg} / \mathrm{m}^{2}:<20 ; 20-25$ (overweight); 25-30; >30 (obese) respectively) and waist girth adjusted for hip girth in 5000 women using unpublished data from the UK National Sizing Survey (JCK Wells, P Treleaven and TJ Cole, unpublished results). Adjusted waist increases markedly with age in each BMI category, demonstrating age-related changes in shape within BMI levels. (c) Waist z-score $v$. hip z-score in 2000 young women from the same sample. All those individuals with values above the regression line have high waist girth relative to hip girth (i.e. a high waist:hip ratio; WHR); however, those individuals with values in the lower left-hand corner of the plot may have a high WHR only because hip girth is small. 
final trimester of pregnancy. However, by the time term age is reached preterm infants often continue to show low levels of body fat (Uthaya et al. 2005; although this outcome depends on early postnatal diet), a trait which is preserved into mid-childhood (Fewtrell et al. 2004). These findings are consistent with the hypothesis that the final trimester of pregnancy is an important period for the programming of fat mass. Despite their reduced total adipose tissue mass, MRI studies have suggested that by term age preterm infants have a more central adipose tissue distribution (Uthaya et al. 2005), with some indication that this trait persists subsequently (MS Fewtrell, A Lucas, TJ Cole and JCK Wells, unpublished results).

A third source of evidence for the fetal programming of body composition derives from studies of maternal metabolic control during pregnancy. Maternal type 1 diabetes and gestational diabetes are both associated with an increased risk of obesity in the offspring (Rodrigues et al. 1998; Whitaker et al. 1998). The influence of type 2 diabetes is more complex, and it might plausibly involve either a programming mechanism or genetic transmission (the thrifty genotype hypothesis). Recent studies of the Pima Indians (Dabalea et al. 2000; Dabalea \& Pettit, 2001), a population characterised by unusually high rates of the disease, have elegantly differentiated between these pathways. Within mothers who at some stage develop type 2 diabetes the risk of the offspring developing the condition is much greater in those born after the diagnosis relative to those born before the diagnosis (Dabalea et al. 2000). The intrauterine diabetic environment is thus associated with an increased risk of obesity in both childhood and adulthood, independently of genetic factors and effects on birth weight (Dabalea \& Pettit, 2001).

There is therefore some indication that adipose tissue mass and distribution may be programmed by experience during fetal life, independently of the contribution subsequently generated by postnatal growth pattern. These fetal effects may function relatively independently of birth weight, the importance of which remains controversial. A recent study (Hemachandra \& Klebanoff, 2006) has shown, for example, that birth weight is reduced following intrauterine growth retardation during the third trimester of pregnancy, but is not reduced if growth retardation occurs during the first trimester of pregnancy. Thus, the ability of birth weight to indicate fetal growth experience is crude, and derives merely from the fact that since all embryos begin life at approximately similar size, birth weight must in some sense represent the magnitude of fetal growth. This proposition is confounded first by the lack of information about body composition, and second by the fact that fetal genotype influences fetal growth, such that birth weight cannot indicate the extent to which genetic growth potential has been achieved. One solution to this dilemma is to use ponderal index rather than birth weight, as a better index of nutritional status (for example, see Wells et al. 2005; Rogers et al. 2006). Another approach has been to categorise intrauterine growth retardation on the basis of disparity between birth weight and adult height (Leon et al. 1996). Such a strategy is ideal for studies of body composition development, but to the authors' knowledge this approach has not yet been adopted when considering body composition. Instead, the vast majority of studies have simply considered associations between birth weight and later BMI or body composition.

An extensive systematic review of factors associated with childhood obesity (Parsons et al. 1999) has identified numerous studies associating birth weight with later BMI, with each kilogram increase in birth weight typically increasing BMI by $0 \cdot 5-0.7 \mathrm{~kg} / \mathrm{m}^{2}$. As BMI is the mostwidely-used categorisation for overweight and obesity, such studies were initially interpreted as indicating that fatter babies subsequently remain fatter. Such a conclusion would be consistent with studies associating maternal gestational diabetes with an increased risk of macrosomic offspring, who do indeed tend to remain obese (Wells, 2007). However, the scenario for diabetic mothers should not be taken to imply a linear association between birth weight and later fatness across the entire range of birth size. Some studies (Rogers \& EURO-BLCS Study Group, 2003) have suggested 'J'-shaped or 'U'-shaped associations between birth weight and subsequent obesity risk categorised by BMI, implying a high prevalence of obesity in those of low or high birth weight. A smaller set of studies has explored associations between birth weight and subsequent regional distribution of fat. However, the findings were inconsistent and, like those mentioned earlier, mostly relied on simple anthropometry to assess the outcome.

Over the last decade, there has been a substantial rise in the number of studies exploring the relationship between birth weight and later body composition in greater detail. These studies have differed in the age range considered, the methods used to assess body composition and in the statistical approaches to analysing the data. Table 1 summarises such studies, addressing indices of lean mass, total body fatness and central adiposity. Despite using a variety of measurement techniques, these studies are fairly consistent, where appropriate data is available, in demonstrating significant associations between birth weight and subsequent lean mass. This association is broadly present across populations, reported, for example, in European and American studies as well as those from Brazil, Guatemala and India, and is apparent across the entire lifespan, the one exception being a study of infants born preterm (Fewtrell et al. 2004), possibly suggesting that preterm delivery disrupts the normal developmental trajectory of lean mass.

In contrast, the findings have been markedly less consistent for body fat and its distribution, with studies variously finding negative, positive or non-significant associations with birth weight (Table 1). This inconsistency appears attributable to a number of factors. First, methodological and statistical variability between studies is implicated (see p. 427, Table 1). Second, results appear to vary according to the time of follow-up. Third, two large studies from developing countries indicate a gender difference in such associations, with birth weight only associated with fat mass in females (Li et al. 2003; Sachdev et al. 2005). Similar findings have emerged from the Avon Longitudinal Study of Parents and Children cohort (Rogers et al. 2006).

Most such studies have focused on the entire spectrum of birth weight, and despite long-standing interest in low 
Table 1. Associations of birth weight with body composition indices during childhood, adolescence, young adulthood and old age

\begin{tabular}{|c|c|c|c|c|c|c|c|c|}
\hline \multirow[b]{2}{*}{ Reference } & \multirow[b]{2}{*}{ Population } & \multirow[b]{2}{*}{$n$} & \multirow[b]{2}{*}{$\begin{array}{c}\text { Age } \\
\text { (years) }\end{array}$} & \multirow[b]{2}{*}{ Outcomes } & \multirow[b]{2}{*}{ Design } & \multicolumn{3}{|c|}{$\begin{array}{l}\text { Results for body composition } \\
\text { indices }\end{array}$} \\
\hline & & & & & & Lean & Fat & $\begin{array}{l}\text { Central } \\
\text { fat }\end{array}$ \\
\hline \multicolumn{9}{|l|}{ Childhood } \\
\hline Hediger et al. (1998) & USA, M+F & 4431 & $\begin{array}{l}\text { 2-47 } \\
\text { months }\end{array}$ & AA, SKF & $\mathrm{R}$ & + & 0 & \\
\hline $\begin{array}{l}\text { Duran-Tauleria et al. } \\
\text { (1995) }\end{array}$ & $U K, M+F$ & 8374 & $5-11$ & W/H, SKF & $\mathrm{R}$ & & + & \\
\hline Okosun et al. (2000) & USA, $M+F$ & 2488 & $5-11$ & SKF & $\mathrm{R}$ & & + & - \\
\hline Mulligan et al. (2005) & $\mathrm{UK}, \mathrm{M}+\mathrm{F}$ & 85 & $6-9$ & DXA, BP & $\mathrm{R}$ & & - & \\
\hline Garnett et al. (2001) & $\begin{array}{l}\text { Australian, } \\
\qquad \mathrm{M}+\mathrm{F}\end{array}$ & 255 & $7-8$ & BMI, DXA & $\begin{array}{l}\text { ANOVA, } \\
\text { R, PC }\end{array}$ & & $-\dagger$ & - \\
\hline Bavdekar et al. (1999) & India, $M+F$ & 477 & 8 & $\begin{array}{l}\text { BMI, WHR, } \\
\text { SKF }\end{array}$ & $\mathrm{R}$ & & + & $-\dagger$ \\
\hline Walker et al. (2002) & Jamaica & 306 & 7,11 & BMI, SKF & $\mathrm{R}$ & & & - \\
\hline Malina et al. (1996) & USA, $M+F$ & 237 & $7-12$ & BMI, SKF & $\mathrm{PC}$ & & & $-\dagger$ \\
\hline Fewtrell et al. (2004) & $\begin{array}{l}\mathrm{UK}, \mathrm{M}+\mathrm{F} \\
\text { preterm }\end{array}$ & 497 & $8-12$ & DXA & $\mathrm{R}, \mathrm{TT}$ & 0 & 0 & \\
\hline Wells et al. (2005) & Brazil, M & 172 & $9-10$ & $\mathrm{BMI}, \mathrm{BIA}$ & ANOVA, $\mathrm{R}$ & + & 0 & \\
\hline Rogers et al. (2006) & $\mathrm{UK}, \mathrm{M}+\mathrm{F}$ & 6086 & $9-10$ & DXA & $\mathrm{R}$ & + & $+\mathrm{F}$ & 0 \\
\hline Singhal et al. $(2003 b)$ & $\mathrm{UK}, \mathrm{M}+\mathrm{F}$ & 164 & $7-16$ & $\begin{array}{l}\text { BIA, DXA, } \\
\text { SKF }\end{array}$ & $\mathrm{R}$ & + & 0 & \\
\hline \multicolumn{9}{|l|}{ Adolescence } \\
\hline Labayen et al. (2006) & Spain, M+F & 234 & $13-18$ & DXA, SKF & $\mathrm{R}$ & + & + & $-M$ \\
\hline Barker et al. (1997) & UK, $\mathrm{M}+\mathrm{F}$ & 216 & $14-16$ & $\begin{array}{l}\text { BMI, WHR, } \\
\text { SKF }\end{array}$ & $\mathrm{R}$ & & & $-\dagger$ \\
\hline Matthes et al. (1996) & $\mathrm{UK}, \mathrm{M}+\mathrm{F}$ & 165 & $15 \cdot 7$ & BMI, SKF & $\mathrm{CC}$ & & 0 & 0 \\
\hline Frisancho (2000) & USA, $M+F$ & 1993 & $15-17$ & BMI, SKF & $\mathrm{R}$ & & 0 & \\
\hline Kahn et al. (2000) & USA, M & 192 & $17-22$ & $\begin{array}{l}\text { BMI, WC, } \\
\text { TA }\end{array}$ & $\mathrm{R}$ & + & + & \\
\hline Euser et al. (2005) & $\begin{array}{l}\text { The Netherlands, } \\
\qquad \mathrm{M}+\mathrm{F}\end{array}$ & 403 & 19 & $\begin{array}{l}\text { W/H, BMI, } \\
\text { SKF }\end{array}$ & $\mathrm{R}$ & + & 0 & 0 \\
\hline \multicolumn{9}{|l|}{ Young adulthood } \\
\hline Li et al. (2003) & $\begin{array}{l}\text { Guatemela, } \\
\qquad M+F\end{array}$ & 267 & $21-27$ & SKF, WHR ${ }^{*}$ & $\mathrm{R}$ & + & 0 & $+\mathrm{F}$ \\
\hline Sachdev et al. (2005) & India, $M+F$ & 1526 & $26-32$ & $\begin{array}{l}\text { BMI, SKF, } \\
\text { WHR }\end{array}$ & PC & + & $+F$ & - \\
\hline Weyer et al. (2002) & USA Pima & 272 & 25 & DXA, UWW & $\mathrm{R}$ & + & 0 & \\
\hline Loos et al. (2001) & Belgium, M & $\begin{array}{l}229, \\
\text { twir }\end{array}$ & irs $18-34$ & BIA, SKF & $\mathrm{R}$ & + & $-\dagger$ & $-\dagger$ \\
\hline Loos et al. (2002) & Belgium, $\mathrm{F}$ & $\begin{array}{r}238 \\
\text { twir }\end{array}$ & irs $18-34$ & SKF, WHR & ANOVA, $\mathrm{R}$ & + & $-\dagger$ & $-\dagger$ \\
\hline \multicolumn{9}{|l|}{ Middle or old age } \\
\hline $\begin{array}{l}\text { Gunnasdottir et al. } \\
\text { (2004) }\end{array}$ & $\begin{array}{l}\text { Iceland, } \\
\mathrm{M}+\mathrm{F}\end{array}$ & 3707 & 50 & SKF & $\mathrm{R}$ & & $-F$ & $-F$ \\
\hline Law et al. (1992) & UK, M & 1084 & 51 or 60 & WHR & $\mathrm{R}$ & & & $-\dagger$ \\
\hline Sayer et al. (2004) & UK, M & 737 & 64 & $\begin{array}{l}\text { BMI, SKF, } \\
\text { WHR }\end{array}$ & $\mathrm{R}$ & + & 0 & 0 \\
\hline Kensara et al. (2005) & UK, M & 32 & $64-72$ & $\mathrm{DXA}, \mathrm{BP}$ & ANOVA & + & $-\dagger$ & $-\dagger$ \\
\hline Gale et al. (2001) & $\mathrm{UK}, \mathrm{M}+\mathrm{F}$ & 143 & $70-75$ & DXA & $\mathrm{R}$ & + & 0 & \\
\hline
\end{tabular}

M, male; F, female; AA, arm anthropometry; BP, Bodpod; DXA, dual-energy X-ray absorptiometry; SKF, skinfold thickness; BIA, bioelectrical impedance analysis; TA, thigh anthropometry; W/H, weight-for-height; WC, waist circumference; WHR, waist:hip ratio; UWW, underwater weighing; CC, case-control study; PC, partial correlation; R, regression; TT, $t$ test; 0 , no association; +, positive association; - , negative association.

†Results significant only after adjustment for current weight or BMI.

birth weight as a predictor of late ill health, few studies have examined in detail the effects of low birth weight on later body composition. Those studies that have done so have confirmed the general association between birth weight and later lean mass but have shown weak or nonsignificant associations with later fatness (Hediger et al.
1998; Kensara et al. 2005; Sachdev et al. 2005; Wells et al. 2005). One study (Kensara et al. 2005) has reported an increased percentage fat in low-birth-weight elderly adults after adjusting for adult BMI, consistent with several others reporting a general inverse association between birth weight and later fatness (Table 1). However, it remains 
unclear whether such a statistical approach is genuinely demonstrating the programming of adiposity, or simply reflects confounding as a result of the association of birth weight with lean mass.

A similar problem concerns investigations of central adiposity. Several studies using simple anthropometry have associated low birth weight with increased waist:hip ratio or subscapular:triceps skinfold thickness, but with the association often emerging only after adjustment for current weight or BMI; while several others have found no such association. The Avon Longitudinal Study of Parents and Children (Rogers et al. 2006) has demonstrated a direct rather than inverse association between birth weight and subsequent waist circumference, and no association between birth weight with truncal fat mass, measured by dual-energy X-ray absorptiometry, after adjustment for total body fat. As mentioned earlier, when associations between birth weight and body composition are dependent on adjustment for current BMI, the appropriate interpretation is that growth patterns between birth and follow up are responsible rather than birth weight itself (Lucas et al. 1999). Thus, it is plausible that these data are best interpreted as demonstrating the programming of reduced lean mass by low birth weight, such that for any given followup weight those individuals maintaining reduced lean mass have a higher proportion of fat in weight. This scenario, requiring statistical adjustment for current size, does not actually link low birth weight directly with increased central adiposity. Resolution of this controversy is likely to require both improved body-composition methodologies and careful statistical analyses.

The studies described earlier have all investigated associations between birth weight and body composition in childhood, and surprisingly little attention has been directed to body composition at birth itself. A particularly intriguing scenario has been reported for low-birth-weight babies from India (Yajnik et al. 2003). In comparison with normal-birth-weight babies from the UK, Indian neonates from Pune were found to have severe deficits in weight and abdominal circumference, but relatively modest deficits in skinfold thickness, especially on the trunk. The authors of the study have suggested that the Indian neonates are characterised by a 'thin-fat' phenotype, having reduced lean mass but preserved truncal fat, and hence a disproportionately high fat mass. At later ages Indians likewise appear to have a disproportionately high fat content for any given BMI value (Wang et al. 1994), hence there is already strong evidence of ethnic differences in physique and body composition, and the Pune data suggest such ethnic differences may derive in part from variability in fetal growth. It remains unclear whether such a thin-fat baby represents a 'thrifty gene' effect, possibly characteristic of Asians, or a 'thrifty phenotype' effect that is characteristic of low-birth-weight infants.

More broadly, associations between birth weight and later phenotype are notoriously difficult to interpret, because of the inverse association between birth weight and subsequent rate of infant weight gain. This inverse association reflects both regression to the mean (a statistical phenomenon) and catch-up (a biological phenomenon) growth. Distinguishing between regression to the mean and catch-up growth is problematic; however, recently Cameron et al. (2005) have suggested that this issue can be addressed if data are expressed in $\mathrm{z}$-score format, allowing adjustment for population regression to the mean.

\section{Postnatal growth and subsequent body composition}

Re-evaluation of the evidence concerning the programming of adult diseases in Western populations strongly suggests that postnatal weight gain is an important component of the process (Lucas et al. 1999). For many aspects of the metabolic syndrome, risk is greatest in those born small who subsequently gain the most weight (Bavdekar et al. 1999; Adair \& Cole, 2002; Barker et al. 2002). Recent studies have begun to distinguish the contributions of different periods of postnatal weight gain to later phenotype and disease risk (Barker et al. 2005), but the generalisability of such findings remains unclear.

As with birth weight, the majority of studies on infant growth rate have used BMI or skinfold thickness as the outcome. Studies are generally consistent in demonstrating a positive association between infant weight gain and later BMI or skinfold thickness (Stettler et al. 2002a,b; 2003; Ong et al. 2000). For example, a recent systematic review (Baird et al. 2005) has found that both large and rapidlygrowing infants have increased risk of subsequent obesity, categorised by BMI. It is less clear, however, the extent to which these studies demonstrate a clear link between early growth and later fatness, as opposed to later size. Very few studies have adjusted childhood body fat for differences in height, even though fast infant growth is associated with greater height subsequently (Sachdev et al. 2005; Wells et al. 2005).

In the large Avon Longitudinal Study of Parents and Children cohort faster infant growth was shown to be associated with greater central adiposity as indicated by skinfold thickness (Ong et al. 2000). In the same study rapid infant growth was found to be associated with indications of growth faltering in utero, being more likely in the offspring of mothers who smoked or who had other clinical signs of fetal growth retardation. This study therefore confirms that associations between birth weight and later fat distribution are generated at least in part by the rate of postnatal growth, but are also associated with prenatal growth patterns.

In contrast to the evidence for birth weight, the effect of infant weight gain on later body composition appears to differ systematically between industrialised and developing countries (Table 2). In European studies greater infant weight gain predicts height, weight, lean mass, fat mass and waist circumference in late adolescence (Euser et al. 2005; Ekelund et al. 2006), while weight at 1 year of age likewise predicts weight, lean mass and fat mass in adults (Sayer et al. 2004). Unpublished data for UK children (approximately 200; S Chomtho, JE Williams, JCK Wells and MS Fewtrell, unpublished results) link infant weight gain with later adiposity, but not with lean mass. In contrast, in three studies from non-Western populations ( $\mathrm{Li}$ et al. 2003; Sachdev et al. 2005; Wells et al. 2005) infant 
Table 2. Associations of infant weight gain with body composition indices during adolescence and young adulthood

\begin{tabular}{|c|c|c|c|c|c|c|c|c|}
\hline \multirow[b]{2}{*}{ Reference } & \multirow[b]{2}{*}{ Population } & \multirow[b]{2}{*}{$n$} & \multirow[b]{2}{*}{$\begin{array}{c}\text { Age } \\
\text { (years) }\end{array}$} & \multirow[b]{2}{*}{ Outcomes } & \multirow[b]{2}{*}{ Design } & \multicolumn{3}{|c|}{ Results for body composition indices } \\
\hline & & & & & & Lean & Fat & $\begin{array}{c}\text { Central } \\
\text { fat }\end{array}$ \\
\hline Wells et al. (2005) & Brazil, M & 172 & $9-10$ & BIA & ANOVA, $R$ & + & 0 & \\
\hline Ekelund et al. (2006) & Sweden, $M+F$ & 248 & 17 & $\mathrm{BP}$ & $\mathrm{R}$ & + & + & + \\
\hline Euser et al. (2005) & The Netherlands, $\mathrm{M}+\mathrm{F}$ & 403 & 19 & BMI, SKF, WHR & $\mathrm{R}$ & + & + & + \\
\hline Li et al. (2003) & Guatemala, $\mathrm{M}+\mathrm{F}$ & 267 & $21-22$ & SKF & $\mathrm{R}$ & + & & \\
\hline Sachdev et al. (2005) & India, $M+F$ & 1526 & $26-32$ & BMI, SKF, WHR & $\mathrm{R}, \mathrm{PC}$ & + & + & \\
\hline
\end{tabular}

M, male; F, female; BIA, bioelectrical impedance analysis; BP, Bodpod; SKF, skinfold thickness; WHR, waist: hip ratio; PC, partial correlation; R, regression; 0, no association; +, positive association.

weight or BMI gain was found to be associated with later weight, height and lean mass, but not with later fat mass.

Whilst further studies are required to confirm this disparity, current evidence suggests that whether infant weight gain is directed to lean mass or fat mass is mediated by the disparity between size at birth and genetic potential. Individuals from industrialised populations, typically near their genetic potential of birth, may be unable to translate increased energy intake into greater lean mass and may be obliged to store the excess energy as fat. On the other hand, individuals from developing or modernising countries, on average small at birth, may have greater capacity to direct any additional energy directly to reducing deficits in lean mass. Consistent with this scenario, it has been shown (Ezzahir et al. 2005; Ibáñez et al. 2006) that catchup growth in small-for-gestational-age infants is associated only with later fatness and the risk of being overweight if the catch-up persists beyond the first year of life.

Such a hypothesis might appear inconsistent with the findings from the Avon Longitudinal Study of Parents and Children cohort, for which catch-up growth was found to be associated with both indices of growth retardation and central adiposity at 5 years. However, in this study rapid growth was quantified over the first 2 years of life, whereas the studies mentioned earlier suggest that the critical window, during which weight gain following low birth weight programmes lean mass, closes within the first year of life. Thus, the findings of the Avon Longitudinal Study of Parents and Children may simply reflect the persistence of fast growth beyond this window, resulting in associations between infant weight gain and later fatness. Further studies with improved study designs and methodologies are required to investigate this issue.

More recently, several studies have focused specifically on the immediate postnatal period. In formula-fed infants weight gain in the first $8 \mathrm{~d}$ of life was shown to be associated with the risk of being categorised as obese in early adulthood (Stettler et al. 2005). Consistent with these data, weight gain in the first 2 weeks of postnatal life in preterm infants was found to be associated with insulin resistance during adolescence (Singhal et al. 2003a). In this randomised controlled trial those participants given a lowernutrient diet were found to have reduced insulin resistance in adolescence, a consequence attributed to slower early growth in this group. The authors subsequently have generalised from this study to propose that 'growth acceleration' after birth, and particularly in the first weeks post partum, itself comprises the primary mechanism by which adult diseases, including obesity, are programmed (Singhal \& Lucas, 2004).

Since the majority of centile crossing in infancy typically occurs very early on, growth acceleration could indeed link low birth weight with later disease risk. However, an alternative explanation for these data could be that the introduction of a high-nutrient diet in the immediate postnatal period programmes hormonal axes rather than growth rate per se, and that the effect on adolescent insulin resistance is derived from such hormonal programming rather than the process of growth itself. The mechanism by which growth contributes to the programming of disease therefore remains unclear, especially since initial catch-up growth seems more favourable in the populations of developing countries, and insulin resistance only appears after infancy (Ibáñez et al. 2006).

The impact of postnatal growth on later body composition is not restricted to the infant period. Weight gain during childhood also appears to exert effects on later body composition. Initial studies suggested that 'adiposity rebound', the age at which childhood BMI reaches a natural nadir before increasing again, was a significant predictor of later obesity (Rolland-Cachera et al. 1987). More recent studies have suggested that such rebound is both a misnomer, in that it refers to BMI rather than adiposity per se (Wells, 2000), and also a statistical artefact since the time of rebound is inherently a function of initial BMI (Cole, 2004). A more appropriate interpretation of these data is simply that those gaining weight rapidly in childhood have a significantly increased risk of obesity subsequently. It is not clear whether childhood weight gain represents programming per se, given that linear growth is by this time canalised, and any effects on fatness are theoretically reversible. Nevertheless, there are some indications that rapid rise through BMI centiles during childhood is a key contributing factor to the risk of heart disease (Barker et al. 2005).

Overall, therefore, growth patterns in both infancy and childhood contribute to the ontogenetic development of body composition and the risk of obesity. Further studies are urgently required in order to elucidate in greater detail relationships between linear growth $v$. weight gain on the one hand, and later tissue masses and tissue distributions on the other. 


\section{Influence of nutrition}

It is not possible to offer here a comprehensive account of the role of early-life nutrition in the programming of body composition. Instead, two important aspects of nutrition will be considered in order to highlight contrasting important issues.

First, there is clear evidence that fetal nutrition underlies early variability in growth but with disparity between the influence of maternal $v$. placental nutrition. Whereas maternal diet during pregnancy and circulating maternal nutrient concentrations show modest or undetectable association with birth weight (Godfrey et al. 1996; Ceesay et al. 1997; Mathews et al. 1999, 2004), maternal metabolism appears to exert markedly stronger effects. The strongest evidence derives from studies of gestational maternal diabetes, a condition that develops in the second half of pregnancy and causes excessive transfer of glucose from mother to fetus. This process in turn induces hyperglycaemia and altered pancreatic structure and function in the offspring, leading to macrosomia and high body fat levels. Follow-up studies suggest an increased risk of childhood obesity (for review, see Wells, 2007). Maternal type 2 diabetes induces similar effects as discussed earlier. Similar findings emerge from studies of maternal blood pressure, with greater blood pressure associated with greater birth weight across the normotensive range (Wells, 2007).

Collectively, such research shows that aspects of increased energy transfer during pregnancy are associated with greater birth weight, and in turn with later body composition. The composition of fetal fuel supply appears key to this association, and it is plausible that stronger effects of maternal pregnancy diet may be uncovered if analyses are extended to maternal glycaemic load and/or response, rather than diet composition itself (for example, see Moses et al. 2006).

In contrast, it has proved to be more difficult to demonstrate a clear impact of early postnatal diet on later body composition. A number of studies have reported that breast-feeding is associated with a decreased risk of later obesity categorised by BMI. Two recent meta-analyses (Arenz et al. 2004; Owen et al. 2005) have supported this hypothesis, and have suggested both categorical and doseresponse protective effects. However, studies that have focused on body composition itself as the outcome have in general failed to support this hypothesis. A large study of adult males from Brazil (Victora et al. 2003) has found no association between breast-feeding and adult body fat in men, while an analysis from the Avon Longitudinal Study of Parents and Children cohort (Toschke et al. 2007) has found a negligible effect of breast-feeding on mean body fat. Although this study has found a small protective effect against being in the top decile of body fat, this effect was shown to be greatly attenuated after adjusting for confounders, reducing any physiological effect attributable to diet itself.

The complex scenario relating to breast-feeding highlights several major difficulties when investigating the role of nutrition in the programming of body composition. First, detailed information about breast-feeding practice is rarely available in large cohort studies. Second, reverse causation may contribute, with those experiencing difficulties breastfeeding resorting to 'aggressive' formula feeding in order to overcome early deficits in the weight gain of their infants. Third, breast-feeding is associated with a variety of social factors, and it is difficult to be confident that diet, as opposed to associated factors, explains subsequent outcome. More generally, randomised controls of early diet are rare, particularly in relation to fetal nutrition, and in the case of breast-feeding are unethical.

Identifying causal roles of nutrition in the programming process is therefore difficult. Nevertheless, the importance of this issue should not be denied, since early-life diet remains implicated in the aetiology of obesity and public health policy requires reliable evidence of this role in order to recommend appropriate dietary practices. Important components of early-life nutrition include not only maternal metabolism and infant feeding mode but also postnatal feeding for those infants born preterm, feeding schedule in the hours following birth and weaning schedule. As with maternal nutrition during pregnancy, infant dietary glycaemic load may well prove to be of importance.

However, it is noted that despite the considerable emphasis directed to the notion of fetal 'undernutrition' as a key factor in the programming of disease, maternal diet during pregnancy appears to exert relatively little effect on offspring birth weight. This small effect is in marked contrast to the impact of maternal pregnancy metabolism (Wells, 2007). Given the rapidly-increasing prevalence of the metabolic syndrome in many populations, reflected in increasing prevalences of obesity, diabetes and hypertension in pregnant mothers, the influence of maternal pregnancy metabolism, as opposed to dietary intake, on offspring body composition merits further attention.

\section{Evolutionary perspective}

The fact that early growth rate predicts later risk of disease might be interpreted as deriving from interactions between human biology and the Western industrialised niche that the human population has entered only recently. For example, CVD represents a relatively new cause of mortality, rarely reported before the 20th century. It would be more appropriate, however, to consider early-life programming as an integral and fundamental component of human biology, and the role of body composition in this process clarifies this position. To focus disproportionately on the 'thrifty phenotype' of low-birth-weight infants as a risk factor for later disease is to miss broader biological patterns, since associations between birth weight and later outcome tend to hold broadly across the entire range of birth weight. When adopting an evolutionary perspective it is helpful to discard the terminology of 'programming' and to refer instead to the 'environmental induction' of phenotype (Bateson, 2001). Such an approach avoids incorrectly suggesting that early environmental conditions in themselves contain specific cues for disease.

All offspring should be regarded as subject to environmental phenotypic induction during early development, with growth trajectory (and later health profile) inevitably 


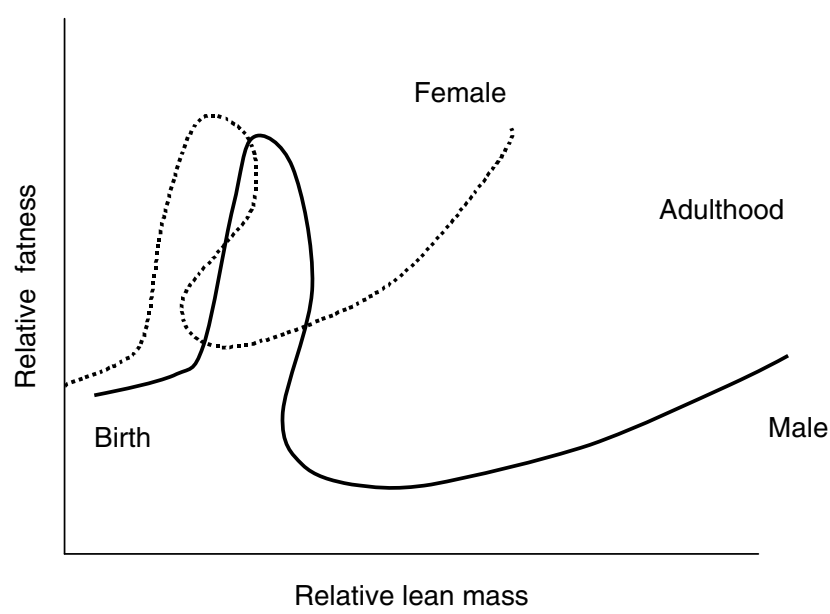

Fig. 2. The life-course development of body composition in men and women, showing the profound divergence in relative fatness that accumulates by early adulthood. Differences in fat:lean are apparent at birth and persist throughout infancy and childhood before becoming strongest during adolescence (for detailed discussion, see Wells, 2006).

being associated with maternal phenotype before conception and during pregnancy and lactation (Wells, 2003). The fact that the two genders show different associations between early growth and later body composition is a further indication that such phenotypic induction is a normal component of human development. It is the interaction between such normal developmental plasticity and relatively-modern environmental factors that is now generating clear associations between early experience and later disease risk.

Evolution has been described as a game in which the reward for genes 'winning' (surviving) in one time period is the chance to 'play again' in the next (Slobodkin \& Rappaport, 1974). Although it is commonly assumed that natural selection acts on traits (e.g. eye colour, height), it is more appropriate to consider strategies as the true target of selection (Houston \& McNamara, 1999). Natural selection has clearly favoured substantially higher levels of body fat in adult females, and of lean mass in adult males (Fig. 2). Such differences have been attributed to the differing energy requirements and behaviours associated with reproductive fitness, with the greater fatness of females aiding the high energy costs of pregnancy and lactation, and the greater lean mass of males plausibly aiding intermale competition or resource acquisition (Wells, 2006). The data reviewed earlier indicate that even in fetal life male and female offspring have begun to pursue different strategies in their relative allocation of energy to somatic tissue $v$. energy stores, with greater early growth associated more strongly with later lean mass in males and with later fat mass in females. This differential energy allocation thus represents differing investment according to likely future returns.

An evolutionary approach may also aid the interpretation of the shift in the target of weight gain at the end of infancy. Before agriculture the post-weaning diet is likely to have had low energy density, such that breast-milk would have represented a high-energy diet that must inevitably cease at weaning. The finding that catch-up growth only induces excess fat deposition after infancy (Ibáñez et al. 2006) suggests that the underlying insulin resistance would, in natural conditions, confer only benefits to low-birth-weight infants, by first increasing the accretion of lean mass during the period of lactation and then losing potency just as growth becomes canalised rather than nutritionally regulated. It has been argued previously (Wells, 2003) that such canalisation has evolved to buffer the greater variability in energy supply that occurs with weaning. In more-modern environments, however, insulin resistance can interact with a high-energy-density diet throughout childhood, resulting in excess fat accumulation from the time point when growth becomes canalised and lean mass loses its plasticity.

\section{Priorities for future research}

A major limitation of existing work on the programming of body composition comprises the lack of information on body composition at birth and during infancy. Given increasing recognition of the inaccuracy of BMI as an index of body fat, there is a need for more direct measurements of tissue masses and their distribution from birth onwards in longitudinal studies.

Historically, research on body composition during early life has been hindered by a paucity of appropriate techniques. Most body-composition techniques are either impractical for infants or of unknown accuracy. Isotope dilution has been used in a number of studies of infants for the last two decades, but follow-up studies have been rare. There are now several techniques that can be used to measure body composition in early life, which include, in addition to isotope dilution, whole-body air-displacement plethysmography and MRI scanning. These techniques should now be used to investigate: first, body composition at birth, and its association with fetal experience; second, body composition during infancy and the effects of variability in growth rate. Such work is likely to make a major contribution to the understanding of the process by which early environmental factors are associated with the risk of the metabolic syndrome, and this research may be particularly important in understanding ethnic disparities in disease risk.

\section{Summary}

The ontogenetic development of body composition is implicated in several ways in the aetiology of the metabolic syndrome. Lean mass has implications for glucose uptake and physical capacity for work and exercise. Fat mass and its distribution has implications for reproductive function and risk of disordered metabolism. Recent studies have invoked a shift from undue emphasis on the consequences of low birth weight to a broader appreciation of the long-term effects of growth throughout the developmental period and across the entire range of body size. Associations between growth and later body composition strongly implicate nutrition as the underlying mechanism. 
However, existing evidence remains sparse, and in the case of breast-feeding, inconsistent. A new focus on body composition itself in early life is likely to make a major contribution to the understanding of the programming of the metabolic syndrome.

\section{References}

Adair LS \& Cole TJ (2002) Rapid child growth raises blood pressure in adolescent boys who were thin at birth. Hypertension 41, 451-456.

Arenz S, Ruckerl R, Koletzko B \& von Kries R (2004) Breastfeeding and childhood obesity - a systematic review. International Journal of Obesity 28, 1247-1256.

Baird J, Fisher D, Lucas P, Kleijnen J, Roberts H \& Law C (2005) Being big or growing fast: systematic review of size and growth in infancy and later obesity. British Medical Journal 331, 929.

Barker DJ, Osmond C, Forsen TJ, Kajantie E \& Ericksson JG (2005) Trajectories of growth among children who have coronary events as adults. New England Journal of Medicine 353, 1802-1809.

Barker DJP, Eriksson JG, Forsen T \& Osmond C (2002) Fetal origins of adult disease: strength of effects and biological basis. International Journal of Epidemiology 31, 1235-1239.

Barker M, Robinson S, Osmond C \& Barker DJ (1997) Birth weight and body fat distribution in adolescent girls. Archives of Disease in Childhood 77, 381-383.

Bateson P (2001) Fetal experience and good adult design. International Journal of Epidemiology 30, 928-934.

Bavdekar A, Yajnik CS, Fall CH, Bapat S, Pandit AN, Deshpande V, Bhave S, Kellingray SD \& Joglekar C (1999) Insulin resistance syndrome in 8-year-old Indian children: small at birth, big at 8 years, or both? Diabetes 48, 24222429.

Cameron N, Preece MA \& Cole TJ (2005) Catch up growth or regression to the mean? Recovery from stunting revisited. American Journal of Human Biology 17, 412-417.

Ceesay SM, Prentice AM, Cole TJ, Foord F, Weaver LT, Poskitt EME \& Whitehead RG (1997) Effects on birth weight and perinatal mortality of maternal dietary supplements in rural Gambia: 5 year randomised controlled trial. British Medical Journal 315, 786-790.

Cole TJ (2004) Children grow and horses race: is the adiposity rebound a critical period for later obesity? BMC Pediatrics 4,6 .

Dabalea D, Hanson RL, Lindsay RS, Pettit DJ, Imperatore G, Gabir MM, Roumain J, Bennett PH \& Knowler WC (2000) Intrauterine exposure to diabetes conveys risks for type 2 diabetes and obesity. A study of discordant sibships. Diabetes $\mathbf{4 9}$, 2208-2211.

Dabalea D \& Pettit DJ (2001) Intrauterine diabetic environment confers risks for type 2 diabetes mellitus and obesity in the offspring, in addition to genetic susceptibility. Journal of Pediatric Endocrinology and Metabolism 14, 1985-1991.

Duran-Tauleria E, Rona RJ \& Chinn S (1995) Factors associated with weight for height and skinfold thickness in British children. Journal of Epidemiology and Community Health 49, 466-473.

Ekelund U, Ong K, Linne Y, Neovius M, Brage S, Dunger DB, Wareham NJ \& Rössner S (2006) Upward weight percentile crossing in infancy and early childhood independently predicts fat mass in young adults: the Stockholm Weight Development Study (SWEDES). American Journal of Clinical Nutrition 83, 324-330.
Euser AM, Finken MJ, Keijzer-Veen MG, Hille ET, Wit JM \& Dekker FW (2005) Associations between prenatal and infancy weight gain and BMI, fat mass, and fat distribution in young adulthood: a prospective cohort study in males and females born very preterm. American Journal of Clinical Nutrition $\mathbf{8 1}$, 480-487.

Ezzahir N, Alberti C, Deghmoun S, Zaccaria I, Czerichow P, Levy-Marchal C \& Jacquet D (2005) Time course of catch-up in adiposity influences adult anthropometry in individuals who were born small for gestational age. Pediatric Research 58, 243-247.

Fewtrell MS, Lucas A, Cole TJ \& Wells JCK (2004) Prematurity and reduced body fatness at $8-12$ y of age. American Journal of Clinical Nutrition 80, 436-440.

Frisancho AR (2000) Prenatal compared with parental origins of adolescent fatness. American Journal of Clinical Nutrition 72, $1186-1190$.

Gale CR, Martyn CN, Kellingray S, Eastell R \& Cooper C (2001) Intrauterine programming of adult body composition. Journal of Clinical Endocrinology and Metabolism 86, 267-272.

Garnett SP, Cowell CT, Baur LA, Fay RA, Lee J, Coakley J, Peat JK \& Boulton TJ (2001) Abdominal fat and birth size in healthy prepubertal children. International Journal of Obesity 25, 1667-1673.

Godfrey K, Robinson S, Barker DJ, Osmond C \& Cox V (1996) Maternal nutrition in early and late pregnancy in relation to placental and fetal growth. British Medical Journal 312, 410-414.

Gunnasdottir I, Birgisdottir BE, Benediktsson R, Gudnason V \& Thorsdottir I (2004) Association between size at birth, truncal fat and obesity in adult life and its contribution to blood pressure and coronary heart disease: studying a high birth weight population. European Journal of Clinical Nutrition 58, 812-818

Hediger ML, Overpeck MD, Kuczmarski RJ, McGlynn A, Maurer KR \& Davis WW (1998) Muscularity and fatness of infants and young children born small- or large-for-gestationalage. Pediatrics 102, E60.

Hemachandra AH \& Klebanoff MA (2006) Use of serial ultrasound to identify periods of fetal growth restriction in relation to neonatal anthropometry. American Journal of Human Biology 18, 791-797.

Houston AI \& McNamara JM (1999) Models of Adaptive Behaviour. Cambridge: Cambridge University Press.

Ibáñez L, Ong K, Dunger DB \& de Zegher F (2006) Early development of adiposity and insulin resistance after catch-up weight gain in small-for-gestational-age children. Journal of Clinical Endocrinology and Metabolism 91, 2153-2158.

Kahn HS, Narayan KM, Williamson DF \& Valdez R (2000) Relation of birth weight to lean and fat thigh tissue in young men. International Journal of Obesity 24, 667-672.

Kensara OA, Wootton SA, Phillips DI, Patel M, Jackson AA \& Elia M (2005) Fetal programming of body composition: relation between birth weight and body composition measured with dual-energy X-ray absorptiometry and anthropometric methods in older Englishmen. American Journal of Clinical Nutrition 82, 980-987.

Labayen I, Moreno LA, Blay MG, Blay VA, Mesana MI, Gonzalez-Gross M, Bueno G, Sarria A \& Bueno M (2006) Early programming of body composition and fat distribution in adolescents. Journal of Nutrition 136, 147-152.

Law CM, Barker DJ, Osmond C, Fall CH \& Simmonds SJ (1992) Early growth and abdominal fatness in adult life. Journal of Epidemiology and Community Health 46, 184-186.

Leon DA, Koupiclova I, Lithell HO, Berglund L, Mohsa R, Vagero D, Lithell UB \& McKeigue PM (1996) Failure to realize growth potential in utero and adult obesity in relation to 
blood pressure in 50 year old Swedish men. British Medical Journal 312, 40-46.

Li H, Stein AD, Barnhart HX, Ramakrishnan U \& Martorell R (2003) Associations between prenatal and postnatal growth and adult body size and composition. American Journal of Clinical Nutrition 77, 1498-1505.

Loos RJ, Beunen G, Fagard R, Derom C \& Vlietinck R (2001) Birth weight and body composition in young adult men - a prospective twin study. International Journal of Obesity 25, $1537-1545$.

Loos RJ, Beunen G, Fagard R, Derom C \& Vlietinck R (2002) Birth weight and body composition in young women: a prospective twin study. American Journal of Clinical Nutrition 75, 676-682.

Lucas A (1991) Programming by early nutrition in man. In The Childhood Environment and Adult Disease, pp. 38-55 [GR Bock and J Whelan, editors]. Chichester, West Sussex: Wiley.

Lucas A, Fewtrell MS \& Cole TJ (1999) Fetal origins of adult disease - the hypothesis revisited. British Medical Journal 319, 245-249.

McMillen IC \& Robinson JS (2005) Developmental origins of the metabolic syndrome: prediction, plasticity and programming. Physiological Reviews 85, 571-633.

Malina RM, Katzmarzyk PT \& Beunen G (1996) Birth weight and its relationship to size attained and relative fat distribution at 7 to 12 years of age. Obesity Research 4, 385-390.

Mathews F, Youngman L \& Neil A (2004) Maternal circulating nutrient concentrations in pregnancy: implications for birth and placental weights of term infants. American Journal of Clinical Nutrition 79, 103-110.

Mathews F, Yudkin P \& Neil A (1999) Influence of maternal nutrition on outcome of pregnancy: prospective cohort study. British Medical Journal 319, 339-343.

Matthes JW, Lewis PA, Davies DP \& Bethel JA (1996) Body size and subcutaneous fat patterning in adolescence. Archives of Disease in Childhood 75, 521-523.

Moses RG, Luebcke M, Davis WS, Coleman KJ, Tapsell LC, Petocz P \& Brand-Miller JC (2006) Effect of a low-glycemicindex diet during pregnancy on obstetric outcomes. American Journal of Clinical Nutrition 84, 807-812.

Mulligan J, Betts P \& Elia M (2005) Programming of body composition: studies in children aged 6.6 to $9 \cdot 1$ years. International Journal of Body Composition Research 3, 97.

Okosun IS, Liao Y, Rotimi CN, Dever GE \& Cooper RS (2000) Impact of birth weight on ethnic variations in subcutaneous and central adiposity in American children aged 5-11 years. A study from the Third National Health and Nutrition Examination Survey. International Journal of Obesity 24, 479-484.

Ong KK, Ahmed ML, Emmett PM, Preece MA \& Dunger DB (2000) Association between postnatal catch-up growth and obesity in childhood: prospective cohort study. British Medical Journal 320, 967-971.

Owen CG, Martin RM, Whincup PH, Smith GD \& Cook DG (2005) Effect of infant feeding on the risk of obesity across the life course: a quantitative review of published evidence. Pediatrics 115, 1367-1377.

Parsons TJ, Power C, Logan S \& Summerbell CD (1999) Childhood predictors of adult obesity: a systematic review. International Journal of Obesity 23, Suppl. 8, S1-S107.

Ravelli ACJ, van der Meulen JHP, Osmond C, Barker DJP \& Bleker OP (1999) Obesity at the age of $50 \mathrm{y}$ in men and women exposed to fine prenatally. American Journal of Clinical Nutrition 70, 811-816.

Ravelli GP, Stein ZA \& Susser MW (1976) Obesity in young men after famine exposure in utero and early infancy. New England Journal of Medicine 295, 349-353.
Rigo J, Nyamugabo K, Picaud JC, Gerard P, Pieltain C \& De Curtis M (1998) Reference values of body composition obtained by dual energy X-ray absorptiometry in preterm and term neonates. Journal of Pediatric Gastroenterology and Nutrition 27, 184-190.

Rodrigues S, Ferris AM, Perez-Escamilla R \& Backstrand JR (1998) Obesity among offspring of women with type 1 diabetes. Clinical and Investigative Medicine 21, 258266.

Rogers I \& EURO-BLCS Study Group (2003) The influence of birth-weight and intrauterine environment on adiposity and fat distribution in later life. International Journal of Obesity 27, 755-777.

Rogers IS, Andy NR, Steer CD, Wells JCK, Emmett PM, Reilly JJ, Tobias J \& Davey Smith G (2006) Associations of size at birth with body composition and fat distribution at age 9-10 years. American Journal of Clinical Nutrition 84, 739-747.

Rolland-Cachera MF, Deheeger M, Guilloud-Bataille M, Avons P, Patois E \& Sempe M (1987) Tracking the development of adiposity from one month of age to adulthood. Annals of Human Biology 14, 219-229.

Sachdev HS, Fall CH, Osmond C, Lakshmy R, Biswas SKD, Leary SD, Reddy KS, Barker DJ \& Bhargava SK (2005) Anthropometric indicators of body composition in young adults: relation to size at birth and serial measurements of body mass index in childhood in the New Delhi birth cohort. American Journal of Clinical Nutrition 82, 456466.

Sayer AA, Syddall HE, Dennison EM, Gilbody HJ, Duggleby SL, Cooper C, Barker DJ \& Phillips DI (2004) Birth weight, weight at $1 \mathrm{y}$ of age, and body composition in older men: findings from the Hertfordshire Cohort Study. American Journal of Clinical Nutrition 80, 199-203.

Singhal A \& Lucas A (2004) Early origins of cardiovascular disease: is there a unifying hypothesis? Lancet 363, 16421645.

Singhal A, Fewtrell M, Cole TJ \& Lucas A (2003a) Low nutrient intake and early growth for later insulin resistance in adolescents born preterm. Lancet 361, 1089-1097.

Singhal A, Wells J, Cole TJ, Fewtrell M \& Lucas A (2003b) Programming of lean body mass: a link between birth weight, obesity, and cardiovascular disease? American Journal of Clinical Nutrition 77, 726-730.

Slobodkin LB \& Rappaport A (1974) An optimal strategy in evolution. Quarterly Review of Biology 49, 181-200.

Stanner SA \& Yudkin JS (2001) Fetal programming and the Leningrad siege study. Twin Research 4, 287-292.

Stein AD, Zybert PA, van de Bor M \& Lumey LH (2004) Intrauterine famine exposure and body proportions at birth: the Dutch Hunger Winter. International Journal of Epidemiology 33, 831-836.

Stettler N, Bovet P, Shamlaye H, Zemel BS, Stallings VA \& Paccaud F (2002a) Prevalence and risk factors for overweight and obesity in children from Seychelles, a country in rapid transition: the importance of early growth. International Journal of Obesity 26, 214-219.

Stettler N, Kumanyika SK, Katz SH, Zemel BS \& Stallings VA (2003) Rapid weight gain during infancy and obesity in young adulthood in a cohort of African Americans. American Journal of Clinical Nutrition 77, 13741378.

Stettler N, Stallings VA, Troxel AB, Zhao J, Schinnar R, Nelson SE, Ziegler EE \& Strom BL (2005) Weight gain in the first week of life and overweight in adulthood: a cohort study of European American subjects fed infant formula. Circulation 111, 1897-1903. 
Stettler N, Zemel BS, Kumanyika S \& Stallings VA (2002b) Infant weight gain and childhood overweight status in a multicenter, cohort study. Pediatrics 109, 194-199.

Toschke AM, Martin RM, von Kries R, Wells JCK, Smith GD \& Ness AR (2007) Infant feeding method and obesity: BMI and DXA measurements at 9-10 years from the Avon Longitudinal Study of Parents and Children (ALSPAC). American Journal of Clinical Nutrition (In the Press).

Uthaya S, Thomas EL, Hamilton G, Dore CJ, Bell J \& Modi N (2005) Altered adiposity after extremely preterm birth. Pediatric Research 57, 211-215.

Victora CG, Barros F, Lima RC, Horta BL \& Wells J (2003) Anthropometry and body composition of 18 year old men according to duration of breast feeding: birth cohort study from Brazil. British Medical Journal 327, 901.

Walker SP, Gaskin PS, Powell CA \& Bennett FI (2002) The effects of birth weight and postnatal linear growth retardation on body mass index, fatness and fat distribution in mid and late childhood. Public Health Nutrition 5, 391-396.

Wang J, Thornton JC, Russell M, Burastero S, Heymsfield S \& Pierson RN Jr (1994) Asians have lower body mass index (BMI) but higher percent fat than do whites: comparisons of anthropometric measurements. American Journal of Clinical Nutrition 60, 23-28.

Wells JCK \& Victora CG (2005) Indices of whole-body and regional adiposity for evaluating the metabolic load of obesity. International Journal of Obesity 29, 483-489.

Wells JCK (2000) A Hattori chart analysis of body mass index in infants and children. International Journal of Obesity 24, 325329.

Wells JCK (2003) The thrifty phenotype hypothesis: thrifty offspring or thrifty mother? Journal of Theoretical Biology 221, 143-161.
Wells JCK (2006) The evolution of human fatness and susceptibility to obesity: an ethological approach. Biological Reviews 81, 183-205.

Wells JCK (2007) The thrifty phenotype as an adaptive maternal effect. Biological Reviews 82, 143-172.

Wells JCK, Fewtrell MS, Williams JE, Haroun D \& Lawson MS (2006) Body composition in normal weight, overweight and obese children: matched case-control analyses of total and regional tissue masses, and body composition trends in relation to relative weight. International Journal of Obesity 30, 15061513.

Wells JCK, Hallal PC, Wright A, Singhal A \& Victora CG (2005) Fetal, infant and childhood growth: relationships with body composition in Brazilian boys aged 9 years. International Journal of Obesity 29, 1192-1198.

Wells JCK, Treleaven P \& Cole TJ (2007) Body mass index and 3-dimensional body shape: the UK National Sizing Survey. American Journal of Clinical Nutrition 85, 419-425.

Weyer C, Pratley RE, Lindsay RS \& Tataranni PA (2002) Relationship between birth weight and body composition, energy metabolism, and sympathetic nervous system activity later in life. Obesity Research 8, 559-565.

Whitaker RC, Pepp MS, Seidel KD, Wriger JA \& Knopp RH (1998) Gestational diabetes and the risk of offspring obesity. Pediatrics 101, 2 e9.

Wilcox AJ (2001) On the importance - and unimportance - of birthweight. International Journal of Epidemiology 30, 13331341.

Yajnik CS, Fall CH, Coyaji KJ, Hirve SS, Rao S, Barker DJ, Joglekar C \& Kellingray S (2003) Neonatal anthropometry: the thin-fat Indian baby. The Pune Maternal Nutrition Study. International Journal of Obesity 27, 173-180. 